\title{
The use of native vegetation as a proxy for habitat may overestimate habitat availability in fragmented landscapes
}

\author{
Mauricio Almeida-Gomes $(\mathbb{D} \cdot$ Jayme Augusto Prevedello • \\ Renato Crouzeilles
}

Received: 3 August 2015/Accepted: 24 November 2015/Published online: 15 December 2015

(C) Springer Science+Business Media Dordrecht 2015

\begin{abstract}
Context Native vegetation is often used as a proxy for habitat to estimate habitat availability in landscapes. This approach may lead to incorrect estimates of the impacts of habitat loss and fragmentation on species, which have not been thoroughly quantified so far.

Objectives We quantified to what extent the loss of native vegetation reflect actual habitat loss by native species in landscapes. We tested the hypothesis that habitat availability declines at greater rates than native
\end{abstract}

Mauricio Almeida-Gomes, Jayme Augusto Prevedello and Renato Crouzeilles have contributed equally to this manuscript.

M. Almeida-Gomes $(\bowtie) \cdot$ R. Crouzeilles

Laboratory of Vertebrates, Department of Ecology, Federal University of Rio de Janeiro, Avenida Carlos Chagas Filho 373, Cidade Universitária, Rio de Janeiro, RJ 21941-902, Brazil

e-mail: almeida.gomes@yahoo.com.br

\section{J. A. Prevedello}

Laboratory of Landscape Ecology and Conservation, Department of Ecology, State University of São Paulo, Rua do Matão, São Paulo, SP 05508-900, Brazil

Present Address:

J. A. Prevedello

Laboratory of Landscape Ecology, State University of Rio de Janeiro, Rio de Janeiro, RJ 20550-900, Brazil

R. Crouzeilles International Institute for Sustainability, Rio de Janeiro, RJ 22460-320, Brazil vegetation and thus is overestimated when it is quantified on the basis of native vegetation.

Methods Using simulations, we quantified how the loss of native vegetation in artificial and real landscapes affects habitat availability for species with different habitat requirements. We contrasted a generalist species, which uses all native vegetation, with 10 habitat-specialist species classified into three categories (interior, patchy and riparian species).

Results Habitat availability generally declined at greater rates than native vegetation for all specialist species. This pattern was apparent for different specialist species in a broad range of landscape types. Interior species always lost habitat availability more rapidly than the generalist species. Most riparian species lost habitat availability more rapidly than the generalist species. Responses of patchy species were more complex, depending on their dispersal abilities and landscape structure.

Conclusions Habitat availability is likely to be overestimated when native vegetation is used as proxy for habitat, because habitat availability will generally decline at greater rates than native vegetation. Therefore, a species-centered approach should be adopted when estimating habitat availability in landscapes.

Keywords Extinction risks - Fragmented landscapes · Habitat reachability - Habitat loss · Probability of connectivity - Species-centered approach $\cdot$ Species persistence 


\section{Introduction}

The process of habitat loss and fragmentation is the main driver of the current worldwide biodiversity decline (Fahrig 2003). Although all species depend on habitat and thus may be affected by habitat loss and fragmentation, there is large variability in their actual responses to this process (Ewers and Didham 2006). A major challenge for ecologists and conservation biologists is to understand the causes of such variability (Henle et al. 2004).

The variability in species responses to habitat loss and fragmentation could result, at least in part, from the mismatch between how species and ecologists perceive the landscape (Betts et al. 2014). Many ecological studies have measured landscapes using human-defined cover types, assuming for example that "habitat" is the same as "native vegetation" (Fischer and Lindenmayer 2007). This assumption has been common, for example, in analysis of species- and density-area relationships, in which "area" is commonly measured on the basis of native vegetation (see e.g. Connor et al. 2000; Rybicki and Hanski 2013). This approach may have led to incorrect estimates of habitat loss and fragmentation for many species (Ewers and Didham 2006; Betts et al. 2014). As an alternative, the adoption of a species-centered approach to estimate habitat amount and availability could increase our ability to predict species' abundance and distribution in landscapes (Betts et al. 2014). For example, species distribution models can be used to estimate habitat suitability for particular species across landscapes (e.g. Cabeza et al. 2004; Keith et al. 2008).

Adoption of the species-centered approach can be essential when studying habitat specialist species, which are frequently highly sensitive to habitat loss and fragmentation (Krämer et al. 2012; Monks and Burrows 2014). Examples are core-dependent species (e.g. birds and insects; Villard 1998; Peyras et al. 2013), riparian species occupying narrow areas within native vegetation (e.g. stream-dwelling amphibians and insects; Almeida-Gomes et al. 2014; Suhonen et al. 2014), and species with naturally patchy distributions (e.g. amphibians and butterflies; Saccheri et al. 1998; Heard et al. 2012). Some studies have shown, for example, that core-dependent species lose habitat disproportionately as native vegetation is reduced, due to an increase in the amount of edges (Villard 1998; Henle et al. 2004).

In addition, even if habitat amount is reduced in the same proportion as native vegetation, this may not be the case for habitat availability. The availability of a particular habitat depends not only on its amount in the landscape but also on landscape connectivity, as disconnected habitat cannot be reached and used by individuals (Saura and Pascual-Hortal 2007). As habitat availability is likely to be critical for population persistence in fragmented landscapes (Fahrig 2003; Awade et al. 2012), it is essential to understand when it can be accurately estimated from native vegetation.

Here, we quantify to what extent the loss of native vegetation reflect actual habitat loss by native species in landscapes. We tested the hypothesis that habitat availability declines at greater rates than native vegetation and thus is overestimated when it is quantified on the basis of native vegetation. To do so, we quantify how the loss and fragmentation of native vegetation affects habitat availability for species with different habitat requirements and dispersal abilities, through an extensive modeling study in artificial and real landscapes from a biodiversity hotspot.

\section{Methods}

\section{Overview}

To quantify the effects of the loss and fragmentation of native vegetation on habitat availability, we used artificial and real landscapes varying in the amount, degree of fragmentation and spatial extent of native vegetation. Habitat availability was quantified for one "generalist" species, which is able to use all native vegetation as habitat, and for species which use only particular habitats within native vegetation (i.e. "interior", "riparian" and "patchy" species; Fig. 1).We also performed a sensitivity analysis to evaluate how the mobility of each species affected habitat availability. We restricted our analyses to hypothetical rather than real species to be able to contrast a wide range of species with different habitat requirements and dispersal abilities. Finally, we also quantified habitat amount for each species in addition to habitat availability. 
Fig. 1 Example of how the reduction of native vegetation (from 100 to $20 \%$ ) affects habitat distributions of different species, in a simulated landscape with a low degree of fragmentation. The generalist species

(a) occupied all native vegetation, whereas the different specialist species (b-k) occupied only more restricted portions within the native vegetation. Interior species occupied only areas of native vegetation located at least 50 or $200 \mathrm{~m}$ away from edges. Patchy species occupied randomlyscattered portions (either 20 or $50 \%$ ) of the native vegetation, in a pattern either highly fragmented or highly clumped. Riparian species were restricted to the margins of rivers located within native vegetation. Two amounts of rivers in the landscape (10 or $30 \%$ ), as well as two buffer distances from river margins (15 and $40 \mathrm{~m}$ ), were considered to delimit the habitat of these species (a) Generalist

(b) Interior $50 \mathrm{~m}$

(c) Interior $200 \mathrm{~m}$

(d) Patchy $50 \%$ clumped

(e) Patchy $50 \%$ scattered

(f) Patchy $20 \%$ clumped

(g) Patchy $20 \%$ scattered

(h) Riparian 40m 30\%

(i) Riparian $15 \mathrm{~m}$ $30 \%$

(j) Riparian 40m $10 \%$

(k) Riparian 15m 10\%

Native cover
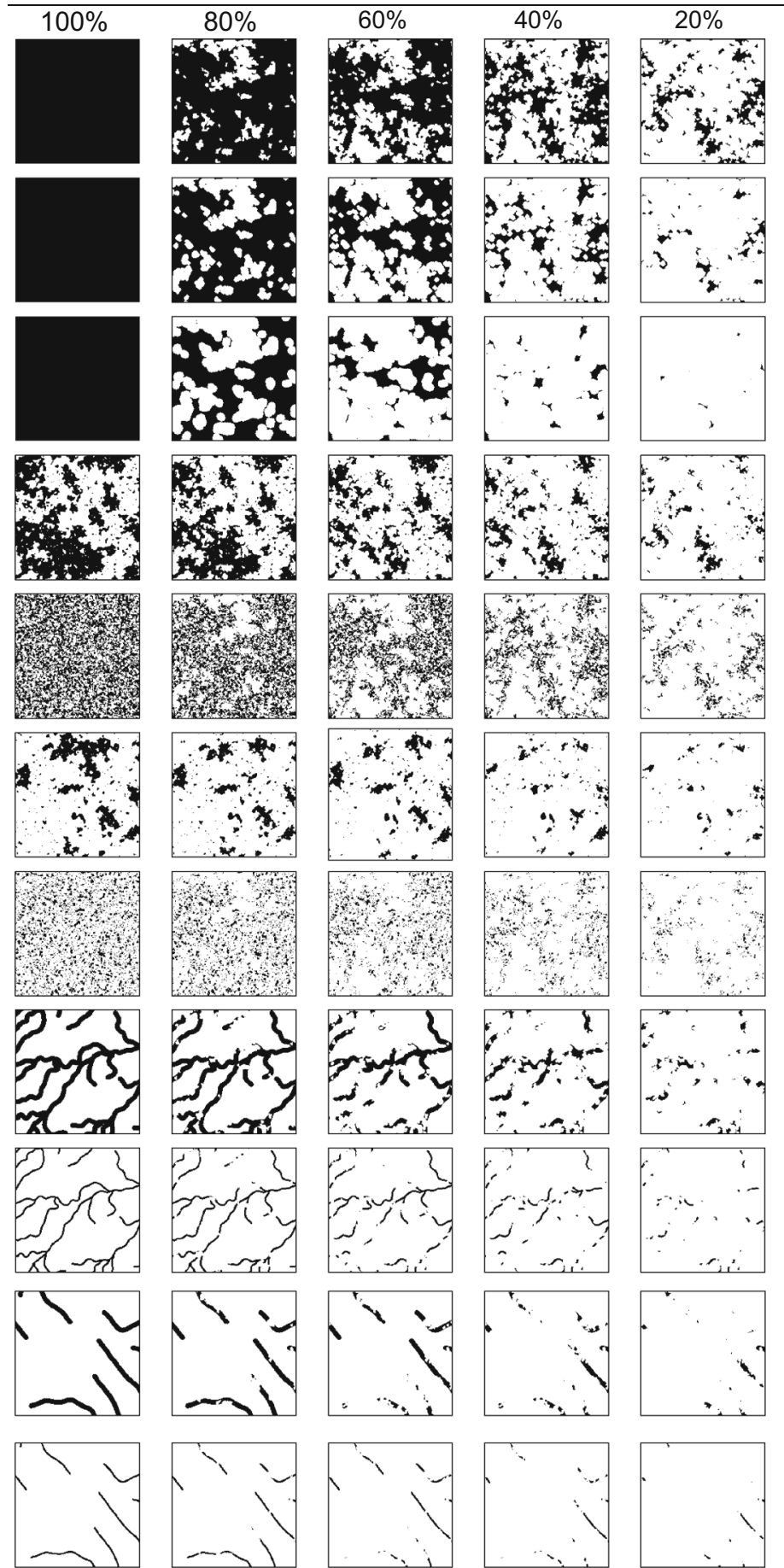
Studied landscapes

We first performed simulations using artificial landscapes generated with the modified random cluster method (Saura and Martínez-Millán 2000). These landscapes had $200 \times 200$ pixels, composed of either native vegetation or matrix pixels. We created fragmented landscapes by sequentially removing native vegetation from an originally continuous landscape (100\% cover), in steps of $10 \%$ ( $\pm 2 \%$; see Fig. 1a), thus simulating the progressive loss and fragmentation of native vegetation. We removed native vegetation by converting native vegetation pixels to matrix pixels, disregarding the location of the particular habitats of each species, thus avoiding any bias in favor or against a particular species. However, removal was not random but controlled by a specific parameter, " $p$ ", with $p=0$ resulting in a completely scattered distribution of native vegetation and $p \approx 0.593$ resulting in a highly clumped distribution (Saura and MartínezMillán 2000). We set $p$ to either 0.10 or 0.56 , to create landscapes with high and low degree of fragmentation in the native vegetation, respectively (see Fig. 1a). We built a total of 200 neutral landscapes, encompassing 10 replicates for each combination of native vegetation (from 100 to $10 \%$ ) and degree of fragmentation ( $p=0.10$ or 0.56 ).

We also conducted simulations on real landscapes of the Atlantic Forest biodiversity hotspot. We randomly selected 100 landscapes from the entire Atlantic Forest, 10 for each percentage of native vegetation, varying from 100 to $10 \%$ in steps of $10 \%$ $( \pm 5 \%)$. For riparian species, we also selected 20 landscapes with either low $(10 \% ; \mathrm{n}=10)$ or high $(30 \% ; \mathrm{n}=10)$ amounts of rivers (obtained from INEA-RJ). This allowed obtaining realistic distributions of habitats for riparian species (see Fig. 1h-k).

For generalist, interior and patchy species, we set pixel resolution in both artificial and real landscapes to $50 \mathrm{~m}$, resulting in landscapes with 10,000 ha, similarly to many empirical and simulation studies conducted in the Atlantic Forest (e.g. Banks-Leite et al. 2010; Crouzeilles et al. 2014). We set minimum patch size to 3 ha (12 pixels) as in the most recent map of Atlantic Forest remnants (SOS Mata Atlântica and INPE 2012). For riparian species, we used the same landscapes, but assumed a pixel resolution of $10 \mathrm{~m}$ (as in the original database) to better depict the linear habitat of these species, resulting in 400-ha landscapes with minimum patch size of 0.12 ha. Comparisons among species were still valid because the analyses focused only on the proportional (rather than the raw) loss of habitat amount and availability for each species. We created a buffer zone of four pixels (corresponding to 40 or $200 \mathrm{~m}$ for riparian or interior/patchy species, respectively) around each landscape to avoid underestimating habitat amount and availability close to landscape boundaries. We treated real landscapes in ArcGis 9.3, and performed simulations in R 2.12 environment (R Development Core Team 2011).

\section{Specialist species}

We considered two "Interior" species, each occupying only areas of native vegetation located at least 50 or $200 \mathrm{~m}$ away from edges (e.g. Ewers and Didham 2008; Banks-Leite et al. 2010; Fig. 1b, c). We considered four "Patchy" species, each occupying either 20 or $50 \%$ of the landscape, in a pattern either highly fragmented or highly clumped (Fig. 1d-g). Such distribution patterns for patchy species were generated in continuous landscapes by using the modified random cluster method (Saura and Martínez-Millán 2000), setting $p$ to either 0.10 or 0.56 (high and low levels of habitat fragmentation, respectively). We also considered four "Riparian" species, each occupying only areas within 15 or $40 \mathrm{~m}$ of river margins (Almeida-Gomes et al. 2014) for landscapes with either low $(10 \%)$ or high $(30 \%)$ amounts of rivers (Fig. 1h-k).

We also varied the mobility of all species due to its potential effect on habitat availability (Saura and Rubio 2010). First, we varied inter-patch dispersal abilities of species as short or large relative to landscape size, setting median dispersal distances as either 100 or $3000 \mathrm{~m}$ for generalist, interior and patchy species (based on Crouzeilles et al. 2014), and as either 4 or $120 \mathrm{~m}$ for riparian species (based on Semlitsch and Bodie 2003). These median dispersal abilities correspond to a probability of $50 \%$ of direct dispersal between two patches (Saura and Pascual-Hortal 2007). Riparian species had lower raw median dispersal abilities because their landscapes were correspondingly smaller; however, relative to landscape size, they had the same dispersal abilities as the other species.

We also varied the ability of species to move through native vegetation, by considering two extreme 
scenarios: (i) native vegetation is completely permeable to movement or (ii) native vegetation and the matrix are equally permeable. In the first scenario, the distance between two habitat patches located at a same patch of native vegetation was zero, whereas in the second that distance corresponded to the Euclidean distance between the two habitat patches. Matrix permeability may affect habitat availability, but we kept it constant in all simulations, focusing on the differential use of native vegetation by each species only.

Quantifying habitat availability and amount

We quantified habitat availability using the Probability of Connectivity (PC; Saura and Pascual-Hortal 2007). This index takes into account both the amount of habitat in the landscape and the functional connectivity, providing a robust measure of the amount of habitat actually available to a species in a landscape (Saura and Pascual-Hortal 2007). $P C$ has been increasingly used as an integrative metric for landscape analysis, because it requires few parameters to be computed (Saura and Pascual-Hortal 2007), is positively correlated with species occurrence in fragmented landscapes (Awade et al. 2012), and is also a good approximation method of metapopulation capacity (Crouzeilles et al. 2015). The $P C$ index varies from 0 , when no habitat is available, to 1 , when the entire landscape is occupied by habitat (see Saura and PascualHortal 2007). We calculated the $P C$ index as:

$P C=\frac{\sum_{i=1}^{n} \sum_{j=1}^{n} a_{i} a_{j} p_{i j}^{*}}{A_{L}^{2}}$

where $n$ represented the number of habitat patches in the landscape, $a_{i}$ and $a_{j}$ represented the sizes of a given pair of patches, $p_{i j}^{*}$ represented the maximum probability of connection between the two patches in the pair and $A_{L}^{2}$ represented the square of the total area of the landscape (Saura and Rubio 2010). The maximum probability of connection $\left(p_{i j}^{*}\right)$ was calculated by considering all the possible paths between the patches ${ }_{i}$ and ${ }_{j}$ (see Saura and Pascual-Hortal 2007 for details).

We also quantified habitat amount for each species, i.e. the percentage of the landscape occupied by the habitat of each species. This analysis ignored the spatial configuration of habitat patches, thus allowing determining whether differences in habitat availability among species were caused by differences in the amount and/or in the configuration of habitat patches.

\section{Results}

Habitat availability

Habitat availability decreased exponentially with the loss of native vegetation for all species in all scenarios simulated (Fig. 2). The interior species always lost habitat availability more rapidly than the generalist species, and this pattern was little affected by species' dispersal abilities or native vegetation permeability. The differences between the generalist and the interior species were less evident in real than in neutral landscapes. Most riparian species lost habitat availability more rapidly than the generalist species, especially when the native vegetation permeability was low. The only exception was the "riparian $15 \mathrm{~m}-30 \%$ ", which behaved similarly to the generalist when native vegetation permeability was high (Fig. 2, rows 1 and 2).

Responses of patchy species to the loss of native vegetation were more complex, depending on their dispersal abilities, the permeability of native vegetation and the degree of fragmentation (Fig. 2). When the permeability or dispersal abilities were high, all patchy species responded similarly to the generalist (Fig. 2, rows 1, 2 and 4). Otherwise, differences between patchy and the generalist species were clear, most of them losing habitat availability more rapidly than the generalist (Fig. 2, row 3).

Habitat amount

Habitat amount decreased linearly with the loss of native vegetation for the generalist, riparian and patchy species in both neutral and real landscapes (Fig. 3). However, for interior species, habitat amount decreased exponentially rather than linearly, occurring more rapidly than the loss of native vegetation. The differences between the generalist and the interior species were smaller and more variable in real (Fig. 3c) than in neutral landscapes (Fig. 3a, b).

\section{Discussion}

Our simulations show that habitat availability is overestimated in most landscapes when native vegetation is used as proxy for habitat, as habitat availability decreases more rapidly than vegetation 

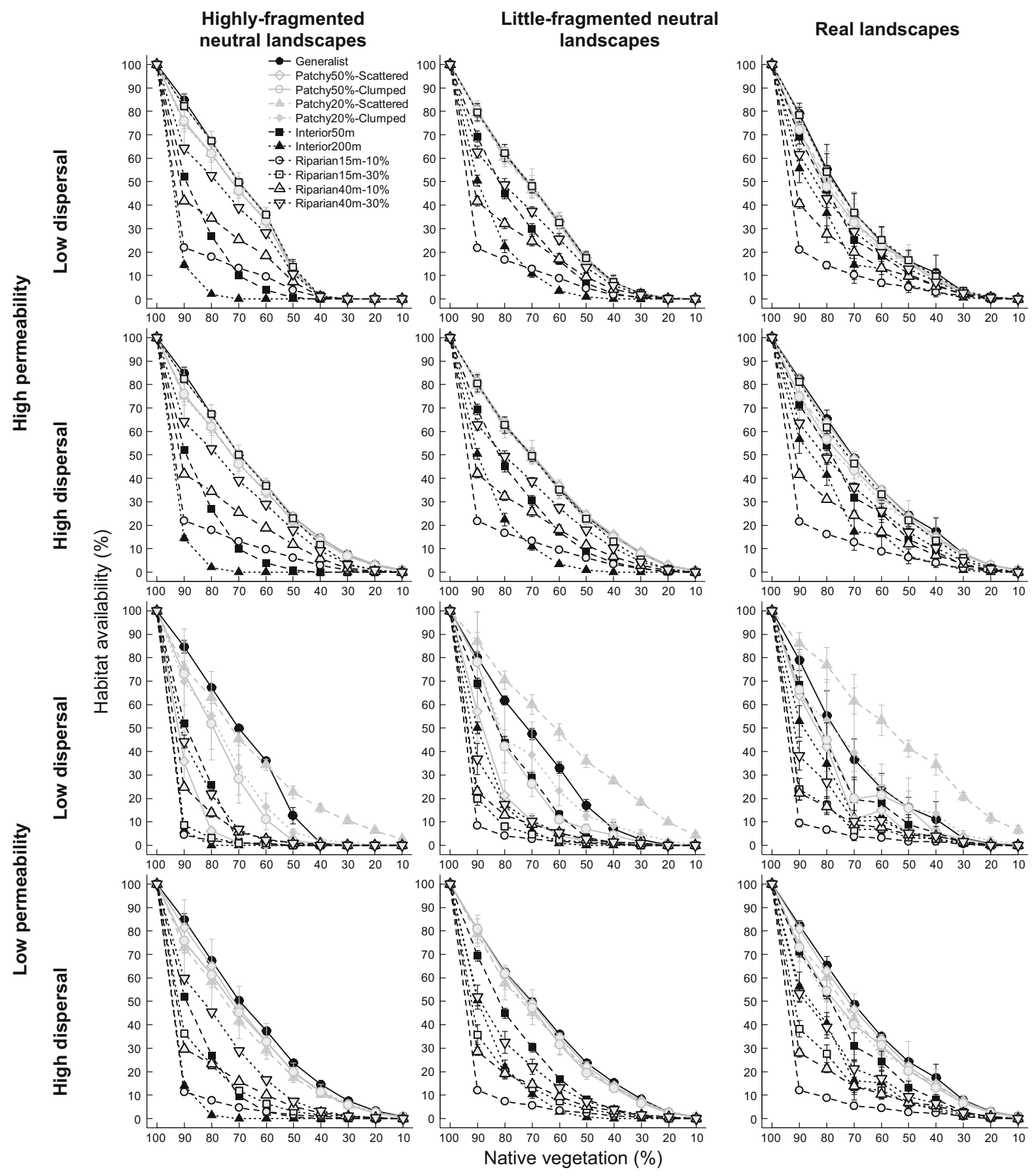

Fig. 2 Effects of the loss of native vegetation on habitat availability (Probability of Connectivity index) for different species. Simulations were performed: (i) when native vegetation is either completely permeable to species movement or as permeable to species movement as the matrix; (ii) in highly- and little-fragmented neutral landscapes and in real landscapes of the Atlantic Forest hotspot; and (iii) for species with different dispersal abilities. Points depict the mean values of the amount of habitat recorded for each species across 10 replicate landscapes at each percentage of native vegetation. Bars represent $95 \%$ confidence intervals calculated across the 10 replicate landscapes, and are sometimes smaller than the points. Depicted values are proportional to the mean values recorded for each species at the original landscapes $(100 \%$ of native vegetation) 

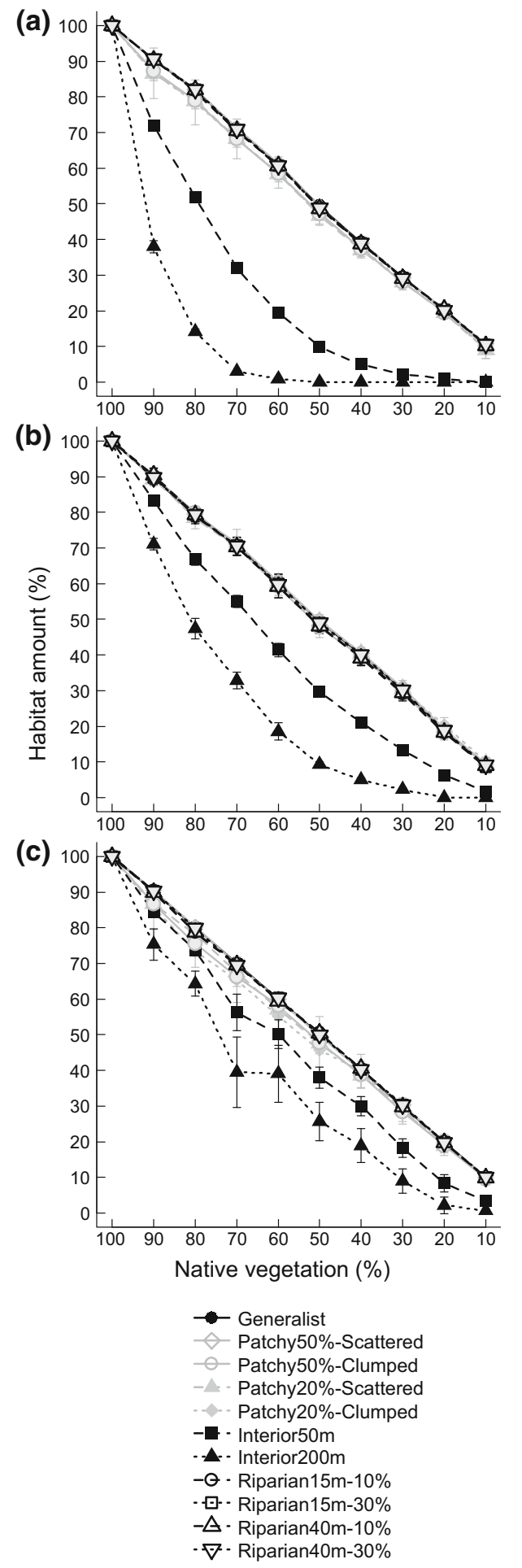

cover. This pattern was apparent for specialist species with different habitat requirements and mobility, in a broad range of landscape types. Therefore, our study
4Fig. 3 Effects of the loss of native vegetation on the amount of habitat for different species. Simulations encompassed highlyfragmented neutral landscapes (a), little-fragmented neutral landscapes (b), or real landscapes of the Atlantic Forest hotspot (c). Symbols as in Fig. 2

supports the claim that a species-centered approach is essential to accurately predict organism's responses to the loss of native vegetation cover (Betts et al. 2014).

The importance of correctly identifying habitat to estimate habitat availability was evident not only when comparing generalists and specialists, but also when contrasting the different specialist species. Interior species were the only species losing habitat amount (in addition to habitat availability) more rapidly than the generalist. This occurs because interior species lose not only those habitat areas that are removed together with native vegetation, but also areas located near habitat edges, as acknowledged in previous studies (e.g. Banks-Leite et al. 2010; Villaseñor et al. 2014). Our study also shows the decline in habitat availability for interior species, which may contribute to explain their disappearance from some highly fragmented landscapes (e.g. Banks-Leite et al. 2010).

Contrary to the interior species, the riparian and patchy species lost habitat amount in the same proportion as the generalist. However, for the riparian species, habitat availability was drastically reduced by the loss of native vegetation, especially when native vegetation was less permeable to species movement. The linear configuration of habitat patches for these species makes them vulnerable to even small losses of native vegetation, which may break habitat apart causing abrupt decreases in patch sizes and increases in patch isolation (see Fig. 1). Such structural changes may reduce habitat availability (Crouzeilles et al. 2014) and possibly population viability (e.g. Öckinger et al. 2010; Mari et al. 2014), and thus may be a key mechanism driving population declines of many stream-dwelling amphibians and reptiles in fragmented landscapes (Gardner et al. 2007; AlmeidaGomes et al. 2014). However, protection of riparian zones by law may reduce the loss of native vegetation and thus the loss of habitat availability for riparian species (Metzger et al. 2010).

Patchy species differed from the generalist only when their mobility was low. When this occurred, 
most patchy species lost habitat availability more rapidly than the generalist, due to the abrupt decrease in connectivity, as reported by Andrén (1994) for random landscapes. Our simulations suggest that responses of patchy species to the loss of native vegetation cover will be complex, depending on their mobility and the amount and degree of aggregation of their original habitat. This variability may explain why some butterfly and plant species with patchy distributions disappear with the loss of native vegetation, whereas others are able to survive even in highly fragmented landscapes (e.g. Devictor et al. 2008; Brückmann et al. 2010). Moreover, some real patchy species could have higher dispersal abilities than generalist species as a result of adaptive responses to habitat patchiness (Fahrig 2007), which could make them equally or even less sensitive to the loss of native cover than more generalist species.

Our findings have important implications for the management and conservation of specialist species in fragmented landscapes. Habitat availability for many specialist species may have been overestimated in landscapes, considering that it is frequently estimated under the assumption that "habitat" is the same as "native vegetation" (Fischer and Lindenmayer 2007; Betts et al. 2014), or at least directly proportional to it. Similarly, many estimates of species loss in communities have been made using species-area relationships, measuring "area" as "native vegetation cover" (Rybicki and Hanski 2013). This is likely to underestimate species loss if many specialist species are present, considering that the true habitat availability for those species is probably overestimated. To accurately predict the extent of habitat and species loss in landscapes, more effort should be expended on estimating the original distributions of species' habitats in landscapes, for example using habitat suitability models (Cabeza et al. 2004; Keith et al. 2008). Despite logistically challenging, the adoption of a speciescentered approach when estimating habitat availability will certainly improve our ability to predict and mitigate the impacts of landscape changes on biodiversity.

Acknowledgments We thank Greet De Coster, Hawthorne L. Beyer and Mariana M. Vale for comments on the manuscript. Financial support was provided by PNPD-CAPES (scholarship to M. A. Gomes.), FAPESP (scholarship to J. A. Prevedello, Project 2013/03457-1), and CAPES/FAPERJ/PAPD (scholarships to R. Crouzeilles).

\section{References}

Almeida-Gomes M, Lorini ML, Rocha CFD, Vieira MV (2014) Underestimation of extinction threat to stream-dwelling amphibians due to lack of consideration of narrow area of occupancy. Conserv Biol 28:616-619

Andrén H (1994) Effects of habitat fragmentation on birds and mammals in landscapes with different proportions of suitable habitat: a review. Oikos 71:355-366

Awade M, Boscolo D, Metzger JP (2012) Using binary and probabilistic habitat availability indices derived from graph theory to model bird occurrence in fragmented forests. Landscape Ecol 27:185-198

Banks-Leite C, Ewers RM, Metzger JP (2010) Edge effects as the principal cause of area effects on birds in fragmented secondary forest. Oikos 119:918-926

Betts MG, Fahrig L, Hadley AS, Halstead KE, Bowman J, Robinson WD, Wiens J, Lindenmayer DB (2014) A species-centered approach for uncovering generalities in organism responses to habitat loss and fragmentation. Ecography 37:517-527

Brückmann SV, Krauss J, Steffan-Dewenter I (2010) Butterfly and plant specialists suffer from reduced connectivity in fragmented landscapes. J Appl Ecol 47:799-809

Cabeza M, Araújo MB, Wilson RJ, Thomas CD, Cowley MJR, Moilanen A (2004) Combining probabilities of occurrence with spatial reserve design. J Appl Ecol 41:252-262

Connor EF, Courtney AC, Yoder JM (2000) Individuals-area relationships: the relationship between animal population density and area. Ecology 81:734-748

Crouzeilles R, Prevedello JA, Figueiredo MSL, Lorini ML, Grelle CEV (2014) The effects of the number, size and isolation of patches along a gradient of native vegetation cover: how can we increment habitat availability? Landscape Ecol 29:479-489

Crouzeilles R, Beyer HL, Mills M, Grelle CEV, Possingham H (2015) Incorporating habitat availability into systematic planning for restoration: a species-specific approach for Atlantic Forest mammals. Divers Distrib 21:1027-1037

Devictor V, Julliard R, Jiguet F (2008) Distribution of specialist and generalist species along spatial gradients of habitat disturbance and fragmentation. Oikos 117:507-514

Ewers RM, Didham RK (2006) Confounding factors in the detection of species responses to habitat fragmentation. Biol Rev 81:117-142

Ewers RM, Didham RK (2008) Pervasive impact of large-scale edge effects on a beetle community. PNAS 105:5426-5429

Fahrig L (2003) Effects of habitat fragmentation on biodiversity. Annu Rev Ecol Evol Syst 34:487-515

Fahrig L (2007) Non-optimal animal movement in human-altered landscapes. Funct Ecol 21:1003-1015

Fischer J, Lindenmayer DB (2007) Landscape modification and habitat fragmentation: a synthesis. Glob Ecol Biogeogr 16:265-280

Gardner TA, Barlow J, Peres CA (2007) Paradox, presumption and pitfalls in conservation biology: the importance of habitat change for amphibians and reptiles. Biol Conserv 138:166-179

Heard GW, Scroggie MP, Malone BS (2012) Classical metapopulation theory as a useful paradigm for the 
conservation of an endangered amphibian. Biol Conserv 148:156-166

Henle K, Davies KF, Kleyer M, Margules C, Settele J (2004) Predictors of species sensitivity to fragmentation. Biodivers Conserv 13:207-251

Keith DA, Akçakaya HR, Thuiller W, Midgley GF, Pearson RG, Phillips SJ, Regan HM, Araújo MB, Rebelo TJ (2008) Predicting extinction risks under climate change: coupling stochastic population models with dynamic bioclimatic habitat models. Biol Lett 4:560-563

Krämer B, Poniatowski D, Fartmann T (2012) Effects of landscape and habitat quality on butterfly communities in prealpine calcareous grasslands. Biol Conserv 152:253-261

Mari L, Casagrandi R, Bertuzzo E, Rinaldo A, Gatto M (2014) Metapopulation persistence and species spread in river networks. Ecol Lett 17:426-434

Metzger JP, Lewinsohn TM, Joly CA, Verdade LM, Martinelli LA, Rodrigues RR (2010) Brazilian Law: full speed in reverse? Science 329:276-277

Monks A, Burrows L (2014) Are threatened plant species specialists, or just more vulnerable to disturbance? J Appl Ecol 51:1228-1235

Öckinger E, Schweiger O, Crist TO, Debinski DM, Krauss J, Kuussaari M, Petersen JD, Pöyry J, Settele J, Summerville KS, Bommarco R (2010) Life-history traits predict species responses to habitat area and isolation: a cross-continental synthesis. Ecol Lett 13:969-979

Peyras M, Vespa NI, Bellocq MI, Zurita GA (2013) Quantifying edge effects: the role of habitat contrast and species specialization. J Insect Conserv 17:807-820

R Development Core Team (2011) R: a language and environment for statistical computing. R Foundation for Statistical Computing. Available from http://www.R-project.org. Accessed Jan 2012)
Rybicki J, Hanski I (2013) Species-area relationships and extinctions caused by habitat loss and fragmentation. Ecol Lett 16:27-38

Saccheri I, Kuussaari M, Kankare M, Vikman P, Fortelius W, Hanski I (1998) Inbreeding and extinction in a butterfly metapopulation. Nature 392:491-494

Saura S, Martínez-Millán J (2000) Landscape patterns simulation with a modified random clusters method. Landsc Ecol 15:661-678

Saura S, Pascual-Hortal L (2007) A new habitat availability index to integrate connectivity in landscape conservation planning: comparison with existing indices and application to a case study. Landsc Urban Plan 83:91-103

Saura S, Rubio L (2010) A common currency for the different ways in which patches and links can contribute to habitat availability and connectivity in the landscape. Ecography 33:523-537

Semlitsch RD, Bodie R (2003) Biological criteria for buffer zones around wetlands and riparian habitats for amphibians and reptiles. Conserv Biol 17:1219-1228

SOS Mata Atlântica, INPE (2012) Atlas dos remanescentes florestais da Mata Atlântica. Fundacão SOS Mata Atlântica, São Paulo

Suhonen J, Korkeamäki E, Salmela J, Kuitunen M (2014) Risk of local extinction of Odonata freshwater habitat generalists and specialists. Conserv Biol 28:783-789

Villard MA (1998) On forest-interior species, edge avoidance, area sensitivity, and dogmas in avian conservation. Auk 115:801-805

Villaseñor NR, Driscoll DA, Escobar MAH, Gibbons P, Lindenmayer DB (2014) Urbanization impacts on mammals across urban-forest edges and a predictive model of edge effects. PLoS ONE 9:e97036 